\title{
General Philosophy of Relationism and Its Application to the Political Theory of State and Society and Implications on Natural Sciences
}

\author{
Igor Janev \\ Institute for Political Studies, Belgrade, Republic of Serbia
}

\begin{abstract}
In the examination and study of the general methodology of science and philosophy, we have discovered a common fundamental problem of the "paradox of the basic element" that creates inconsistencies in social and natural theory and general ontology and epistemology. Our study of the interactions of states as major international actors leads us to the conclusion that the unsolved "paradox of the basic element" of the general systems theory (GST) applied in the neorealist doctrine of international relations generates apparent fundamental theoretical weaknesses that have to be resolved. Therefore, herein we propose a solution to the paradox of the basic element on an ontological level by showing that not the element, but rather the relation is the basic "entity" of the system. Such an approach, where the relationship is the most fundamental category and plays a primary role in the system, transforms the GST into a relationist theory (systemic relationism) that includes the relevant systemic variables both in the system as a whole and in its subsystems (or elements). At the same time, due to the equivalence of the "paradox of the basic element" with the paradox of existence of anything or everything (usually formulated as "Why everything [that is] exists” [and not just nothing]), our relationist approach proves to be a good methodological tool for resolving this fundamental question of the general ontology. In addition, this new approach seems to resolve even the basic problem of natural philosophy formulated as the origin of natural force (F). The relationism formulated in our study provides an answer for the existence of anything (E) in relation to nothingness $(\mathrm{N})$, and then through equivalence of basic relation and interaction explains natural force (s) (F) studied in physics. The basic relation in form of irreducible and inseparable $\{\mathrm{E}, \mathrm{N}\}$ system or $\{\mathrm{E}\}<->\{\mathrm{N}\}$, (where $\mathrm{E}$ - everything, $\mathrm{N}$-nothingness), represents in the physical world a basic irreducible interaction, e.g., a category of force defined in physics (as intensity of interaction). Thus, by applying the same relationist methodology for understanding the physics of force, we provide a fundamental answer related to the origin of force (in the universe). However, besides natural and social applications, in the present article, we discuss how relationism can be used to resolve controversies in the mainstream political theories of state and to provide new original explanation of the origin of state and causes of social development and change. One of our basic conclusions related to the genesis of state is that this supreme institution was historically (systemically) created as a result of struggle for the monopoly of force when the legal idea of titulus (a title of leader/ruler that could be subject of inheritance) emerged. Rulers (i.e., first kings, as successor of primitive tribal chiefs) developed and established legitimacy and appropriate binding rules or laws related to that supreme title to justify their special status (titulus).
\end{abstract}

Igor Janev, Ph.D., Principal Research Fellow, Scientific Advisor/Full Professor, Institute for Political Studies, Belgrade, Republic of Serbia. Janev has published many scientific articles and more than twenty books and monographs in the scientific areas of International Law, International Organizations, International Relations, Diplomacy, and Political, State and Constitutional theory, Political philosophy and the Political methodology. 
Keywords: relationism, interaction, system, force, element, state, law, existence, everything

\section{Introduction}

In our research related to general methodology of change and movement, particularly in the fields of social and political changes, we discovered that at least on the level of a comprehensive doctrine and holistic philosophy, the principles of Marxist-dialectic theory may be successfully implemented. Our general hypothesis was that dialectic methodology can be equally well implemented in (neo-)realistic approach and in the same time applied in the modern neoliberal theory, that is presently based on sociological structural-functional method(s) formulated by Merton (1996). Our findings and conclusion related to international neorealist theory (formulated by Waltz, 1979) based on some elements of the general system theory (by Von Bertalanffy, 1971), proved striking interconnection between general system theory (GST) and dialectic methodology.

The overcoming of inherent weaknesses of the modern political philosophy of state requires indeed a rethinking and reformulation of the basic ideas in the general methodology. Special attention in the present article is therefore devoted to the development of new general holistic systemic philosophy and methodology and its application to answers of most fundamental character, such as "Why everything (that is) exists" (and not just nothing) as a question that is equivalent to the "paradox of the basic element". After the formulation of our new general methodology of systemic (dialectic) relationism, we discovered the usefulness of that approach for a theoretical explanation of the origin and behavior of a state as an institution characterized with possession of the monopoly of (social) physical force. Unlike in the theories of E. Cassirer and J. Kaipayil, where the supremacy of the relation in the system is taken as a postulate, we have derived the fundamental character of the relation in the system by addressing the basic ontological problem "why is there something, rather than nothing”, formulated also by Leibniz in his Principles of Nature and Grace. In Heidegger's (2000) reformulation of the problem, "something" is replaced by "Everything" and "nothing" by "Nothingness".

Using the principles of dialectic methodology and general systems theory (GST), it was logically derived that the existence of the opposing poles $\{\mathrm{E}\}<->\{\mathrm{N}\}$, (where $\mathrm{E}$-everything, $\mathrm{N}$-nothingness) in the ontological problem results from the fundamental relation uniting them as basic systemic entity. We found that the relation in a system is the carrier of certain interaction between two (or more) units in the system, between groups of units in the system, and it is a condition sine qua non for the existence of the system itself. The dynamics of the system (changes, evolution, stability, and other properties) are determined by the relations in the system.

\section{Philosophical Basis of Relationism}

The modern philosophical approaches to the social theory of change and political doctrines of a state and international relations (particularly as external environment that determinates a state behavior) are partially contained in the Marxist-dialectic philosophical methodology and doctrine. This political doctrine and general philosophy is based on four universal dialectic principles (Hegel, 1977; Engels, 1968): (1) in any phenomenon of whatever kind, or element of any structure, there is constant conflict and unity of internal contradictions, which are the prerequisites and drivers of permanent changes in the phenomena, structure(s) or its element(s). A logical derivative of this dynamical principle is that any element $a$ is never absolutely identical to itself ( $a \not \equiv$ 
a) ${ }^{1}$; (2) the principle of negation of (any) negation, as a necessary element of the changes and the dynamics; (3) transformation of the quantity into a new quality at a given critical level of the change of the quantity; and (4) due to the principle of conflicting contradictions and the dynamics of double negation, as well as due to the total inter-connection and interaction between all elements and structures, there is a constant change in any element, structure and of the totality in nature and society. The holistic dynamics is explained by the changes and movement in the elements of the totality, as well as by the changes, movement and transformation of the totality, as a whole (Engels, 1968). The societal implications of these principles are that the economic, social, and cultural dynamics should have a decisive impact on the domestic and foreign policy of states and on the international relations. It is apparent, however, that the above principles of classical (Marxist-) dialectic approach (McTaggart, 2005) are formulated too broadly to provide a useful methodological tool with predictive power in the analytic research of natural and social phenomena. The overwhelmingly general (and, therefore, insufficiently precise) character of these principles may in many instances lead to incorrect conclusions, particularly in the research fields of natural sciences (e.g., failing to support some of the findings of modern physics on the structure of matter). The classical dialectic approach has, however, proved to be relatively successful in the domain of social sciences.

The basic premises of general systems theory (GST) are similar to the principles of dialectic doctrine. They are: (1) the totality of a system of elements and their interactions creates regime; (2) the openness (also in a logical sense) of this totality is the main feature of the dynamic regime; (3) there is a dynamical, inter-connected movement and change of any point, pole and element of this “totality”, as well as a (dynamical) creation of collective features and collective behavior. This principle includes synergism and introduces collective variables characterizing the system as a whole; (4) there is an influence of any element to any other regime's element, and to the dynamics of "totality”, as a whole; and (5) there is dynamic self-regulation of all collective movements of the elements, poles and the "totality" (Von Bertalanffy, 1971).

It is apparent that the general systems theory (GST) takes a more or less organic approach. Similarly, to the dialectic theory, its open totality is driven by the interaction and movement of the elements that create regimes. What had a real impact of GST on the political science was the introduction of two (sometimes more) levels of variables that explain the internal and external behavior of states. However, it can be noticed that while the dynamic inter-connection of elements, and the connection of this dynamics with that of the system as a whole, are adequately enshrined in the GST including in the field of social theory (see neorealism by Waltz, 1979), the element itself is treated as a structureless component of the system only, although possessing interactive attributes. The origin of these attributes and their character, particularly with respect to the interaction of the element with other elements in the system, is not elucidated in the GST. Obviously, it must be rooted in the element's structure and (its) dynamics. Furthermore, if the "element" of the system has its own structure and dynamics, it must be considered on its own right as a system (or sub-system), characterized by its own systemic variables. This logical chain can be continued. The existence of interactive attributes of a structureless element appears as a paradox in the GST.

On the basis of general systems theory (GST), Waltz (1979, pp. 93-101) constructed his famous neorealist paradigm. The Waltzian systems theory of International Relations is based on three main pillars: (1) ordering

\footnotetext{
${ }^{1}$ This principle does not negate, however, that in absence of a time- (or logical) process, when the change of time is almost zero, this non-identity relation transforms itself into an absolute identity, $a \equiv a$. This is the case when the time related to a process (or a logical process) converges absolutely and approaches the zero value.
} 
principle, which relates to the organization of the power within the system; (2) the character of the units of the system, which relates to the capabilities of states as the only international actors, creating the behavior of its individual parts; and (3) the distribution of capabilities among units, as a systemic aspect. Namely, the distribution of capabilities is not an attribute of the units, but a "system-wide" concept (Waltz, 1979, p. 98). This theory has improved on a substantial scale the existing international relations theory, particularly its research methodology. Nevertheless, its systemic aspects are limited, since there is a level where systemic behavior is not fully explained. Namely, units themselves represent minimized systems, where their variables are defined through domestic local dynamics, sometimes not less relevant level-variables than the variables and dynamics at the international level. However, the Waltzian systems theory omits this important level of variables and restrains the systemic logic to the level beyond the system's parts, these later being described as units (i.e., states). As we have seen, the GST does not explicitly make this limitation, but nevertheless treats the fundamental elements as (structureless) systemic components, not fully different or separated from the general and particular systemic behavior. The Waltzian theory seems to consider only the systemic aspects (variables) of the system as a whole; the variables defining the dynamics within the individual units (states) in the system are omitted completely in this theory. The Waltzian approach, based on the "atomistic" nature of the units, is convenient to elegantly construct the system and analyze its properties as a whole, but does not provide an insight into the causes of (or motives for) change within the system and its changing evolution. In the Gilpin's (1981) international neorealist approach, the units of the system are recognized as much more active elements that carry an inherent tendency for expansion and domination. Their motivated activity changes the distribution of power in the system, and thereby the state (regime) of the system. In reality, however, the behavior of the units within the system is not determined a priori, as assumed in any realist theory, but it is a result of certain internal dynamics in the individual units, or in a particular part of the system. All this indicates that the changes (dynamics) of the system cannot be described in terms of systemic variables only, but require inclusion in the analysis also variables on the unit level. These shortcomings of neorealist theories have their root in the GST (on which they are based) in which the basic element of the system is also considered structureless, although possessing interactive capabilities. In contrast to the GST, dialectic doctrine breaks the atomistic nature of the system's unit. According to the principle of unity of contradictions, any part of the system (including the "units") contains an opposite, mutually contradicting part, the antagonistic tension between which is responsible not only for the changes in themselves but also for their interaction with the other parts of the system. Therefore, the structure and the processes within the parts (or units) of the system affect the system as a whole. It is obvious that this logical principle entails division of the parts or elements of the system ad infinitum.

In order to resolve the inconsistencies of GST in this article, we develop a conceptually new approach in which the relation, and not the "unit" or element, plays the dominant role in defining the structure and behavior of the system. By breaking the basic unit of Waltzian system (and, hence, of the GST) in order to resolve the paradox of the existence of (in principle variable) interactive attributes of the structureless unit of this system, the dialectic doctrine, through its principle of unity of contradictions (that implies division of a system's element ad infinitum), introduces its own paradox: the existence of the (basic) element itself. The process of infinite division obviously negates that existence.

The question of existence of the element is obviously an ontological question. To ask how come that the element exists is logically equivalent to the question: How come that "Everything that is" (Sein) exists 
(Heidegger, 2000) ${ }^{2}$. The logical formulation of that fundamental question has to be in an operational form that includes the negation of "Everything that is", namely: How come that Everything that is exists besides the (expected) Nothingness? Nothingness is defined here as all what has left when we put aside the Everything. Since there is empirical evidence that something exists ("at least our thoughts exist"), the origin of Everything, as negation of Nothingness, can be resolved if the question is put in the following symmetric (or oppositional) form: How come that Everything exists in relation to Nothingness? Since we know that something exists (empirically, at least), for resolving the above question, we would have to examine when such question-the origin of Everything (further in the text abbreviated as E) in relation to Nothingness (further in the text abbreviated N)—is logically reducible to absurd, i.e., to an ill-posed question. The answer is derived either in negation of E or negation of N. Because we empirically observe that something (or, for that matter, Everything) exists, the question is how to negate the possibility of the other pole: the Nothingness.

The answer to this basic question can be derived if we combine the principles of GST with the principles of dialectic methodology. Due to the logical equivalence of the paradox of the existence of everything and the paradox of existence of the element, we shall confine our derivations to resolving only the second paradox. However, the equivalence of the two problems will always be kept in mind and included in the derivations when appropriate. We remind that the logical paradox of existence of the element results from the dialectic principle of unity of contradictions triggering the changes, implying a process of division of the element ad infinitum.

In resolving the paradox of infinite division (or "elementaristic paradox"33), we shall apply the dialectic principles of negation of the negation and the transition of quantity to quality. The later principle states that the change of quantity creates, at a certain critical level, a new quality. This presumes that in any continuing process of change, there is always a non-zero quantity for any existing quality. In the process of infinite division of the element, we have to suppose that the quantities of the two sub-elements, forming the element, converge to a zero quantity at infinity. The basic question becomes whether one or both of these two (sub-) elements reaches the zero-quantity value. Reaching the zero-quantity value is certainly a critical level of change of the quantity, and it has to be accompanied by creation of a new quality. The zero-quantity value itself represents that new quality. On the other hand, the dialectic principle of unity of contradictions requires that any change of the quality must be provided through the tensions of contradictions, carried out in the case of element's division by its sub-elements. The role of contradicting elements in triggering the change is, however (and by definition), never absolutely symmetrical; the equilibrium of the tensions would never produce a change in quality. This implies that, in the infinite process of element's division, only one of its sub-elements can reach the zero-quantity value, i.e., can transit into a new quality. Remarkably, in this separation of sub-elements, their contradiction is not lost; it is only transformed into another, more fundamental contradiction between two qualities: one with a non-zero quantity (hence, existence), the other with a zero-quantity value (i.e., non-existence). Both sub-elements cannot reach the zero-quantity value simultaneously also because that would

\footnotetext{
2 The question of the origin of the element is essentially identical to the question of the origin of Everything that exists. This becomes apparent if we take the case when in the set of everything that exists there is only one single element. Resolving the paradox of existence of the element is then logically equivalent to resolving the paradox of the origin of everything that exists, since both questions are basically related to resolving the relation of either the basic element or Everything that exists with the opposing pole of Nothingness, as absence of something. The two paradoxes are, therefore, reduced to single logical paradox of the existence.

3 Paradox that could be formulated as "How come that element(s) exist".
} 
mean that the prerequisite contradiction, necessary for the convergence towards the zero value to take place, would have ceased to exist ${ }^{4}$. If both elements reach the zero-quantity value, i.e., attain the same quality, they become indistinguishable and, by virtue of the Leibniz principle (that entities with all their attributes identical are one and the same entity; see Ray, 2008), they represent one and the same entity. Thus, the asymmetrical contradiction between the sub-elements precludes the possibility that they both simultaneously reach the zero-quantity value, defining the non-existence of quantity or the Nothingness ${ }^{5}$. If only one sub-element reaches the zero-quantity value (negation of quantity), the other one, with a non-zero quantity, has to be defined as something (or, generally, Everything), i.e., that what does not have a zero-value status ${ }^{6}$. As mentioned earlier, the reaching of zero value status by one of the sub-elements creates a new type of contradiction: One of the poles of this contradiction is the Nothingness (N), and the other one is the Everything (E).

From the point of view of GST, E and N, being in contradiction to each other, i.e., mutually connected, form a system. The most essential characteristic of this system is the intrinsic inter-connection of $\mathrm{E}$ and $\mathrm{N}$ without which neither of them can be, nor the system they form can exist. This intrinsic inter-connection of $\mathrm{E}$ and $\mathrm{N}$ in the system constitutes a relation between $\mathrm{E}$ and $\mathrm{N}$ that makes the system possible. The substance of this relation is the contradiction between $\mathrm{E}$ and $\mathrm{N}$ itself. Since from the point of view of GST, the entities $\mathrm{E}$ and $\mathrm{N}$ are mere elements of the system, it follows that the existence of a relation between $\mathrm{E}$ and $\mathrm{N}$ is a prerequisite for their own existence (as elements of the system) and of the system itself. It appears, thus, that the relation is a more fundamental entity in the system than the elements of the system. The system $\{E, N\}$ is obviously the most fundamental one, and the relation between $\mathrm{E}$ and $\mathrm{N}$ can be called fundamental relation. It should be emphasized that the relation has a systemic nature: It cannot exist outside the system, in the same way as the system cannot exist without it. The fundamental nature of the relation originates from the fact that it represents an abstract form of an interaction (e.g., the contradiction between $E$ and $N$ in the above example), that gives the identity and the very existence of its poles (the interacting elements of the system) ${ }^{7}$. Although the relation (as the interaction itself) is most often conceived as being bipolar, in a complex systems it can take a more complex, multi-polar form(s). Within the relationist approach, the paradox of existence of the element (related to the process of infinite division of elements) has, as we have seen above, a natural resolution: The process of infinite division reaches its end at the level of fundamental relation, when the pole of zero quantity and quality cannot be further divided (due to the Leibniz principle, for the origins of term relationism, see Erman, 1979). The non-zero quantity pole (the element) acquires its existence only in the systemic relation with the zero-quantity pole (the absence of the element). Similarly, the question "how come that Everything (E) that is exists" can be resolved only if Everything is in a systemic relation with the Nothingness $(\mathrm{N})$. E and $\mathrm{N}$ are only poles of the fundamental relation that creates them. The origin of both $\mathrm{E}$ and $\mathrm{N}$ is their systemic relation from

\footnotetext{
${ }^{4}$ If a contradiction does not exist, the process of element's division will not proceed at all and will not result in a zero-quantity status for either of the sub-elements. In absence of a contradiction, the principle of negation of negation would not operate, and the inclusion of time in any process would not be necessary.

${ }^{5}$ Furthermore, in the dialectic time-process, both sub-elements are by definition not absolutely identical, at least because they represent different and opposing poles, or sub-elements in contradiction, with different role in the mutual interaction. The necessity of a non-zero quality (or, equivalently, a quantity different than zero) must be first preserved in the basic interaction, at least for the character of one interacting pole/element, in order to create the prerequisite for a changing movement, based on that contradiction.

${ }^{6}$ We call the zero-quantity level a zero value status to indicate the transition of quantity (of something) into a new quality (nothing).

7 This is analogous to the fundamental role of the interaction in modern theories of elementary particles of nature where the interaction, represented by a physical field, generates the interacting particles and not vice versa.
} 
which they are inseparable. The relation includes in itself its poles. Thus, the above formulated question becomes meaningless, i.e., it is reduced to absurd.

\section{Relationist Approach to “Genesis of the State” Theory}

As we have argued in the preceding section, the fundamental nature of the relation originates from the fact that it is only an abstract expression of an interaction that have two poles, conceived in the GST as "elements" (or "units") of the system. Obviously, the smallest system must contain at least two interacting elements, i.e., it must include at least one relation. If the two elements do not mutually interact (i.e., if there is no relation), then they cannot be considered to form a system. The existence of a systemic relation is, thus, a prerequisite for the existence of a system. The complexity of a system is defined by the number of systemic relations that it contains. A systemic relation is fundamentally characterized by its intensity and character. With respect to the properties (i.e., the character), the relations can be of two basic types: "contradiction" (or in social context competition or struggle) and "non-contradiction" (by nature adhesive or cohesive co-operation). The intensity of a relation depends on the amount of capacity of each of the elements (poles) involved in the relation. This property of the element depends on internal factors (by definition the size of internal variables) and represents its potential for interaction with other elements in the system (or interactive power, i.e., interactive intensity) and consequently the intensity of interaction defines the force $(\mathrm{F})^{8}$. Force (as a measurement of interaction) in society (as in physics/nature) is the capacity to cause a (physical) change or movement (work). By classical mechanical (physical) definition, force is a change of velocity (or acceleration) of objects (with certain attributed mass). ${ }^{9}$ So, whenever we discuss herein the interaction(s), as a relationistic category, we can use the term force $(\mathrm{F})$ that is to some extent inter-exchangeable term with the term dialectic contradiction (as one type of relation, as a cause of movement). ${ }^{10}$ In society, the totality of relations in a system defines (its) regime and change. The emergence of a state as an organization (new social quality) steams from systemic production and redistribution of wealth, where possession of power becomes (for the very first time) the ultimate most desirable (profitable) good (or value). In the competitive social environment, and in systemic competition for power, the society creates monopoly of physical force, institutionally formulated as sovereignty. A sovereignty is an absolute monopolistic power or a force concentrated in hands of one or a few people (by definition political elite or rulers). Even the ancient pre-state people(s) were able to understand that by possessing leadership and power over others, they can achieve more wealth and general prosperity. They realized that more benefits with much less own energy invested can be achieved, if they use the power (work) of others in their favor, instead of own energy, e.g., under fair or equal conditions (in hunting, farming, producing, etc.). In the same time, an integrated collective energy and force proved to be less expensive/demanding and much more efficient than personal or individual energy, work or hardship that was needed to create material wealth and means for survival or prosperity. It should also be noticed that, at individual level, every human being naturally possesses a capacity or potential for self-awareness accompanied with self-interest (relationally vis a vis others). This individual feature can transform, at a group level, into systemic competitive collective-interest. This is always a case in the unsafe complex social (competitive) environment. Relationistic approach explains human nature as predominantly socially determined natural potential (for interaction) that is inherently predetermined

\footnotetext{
${ }^{8}$ In physics a basic category Force (F) by definition represent a measurement of interaction.

9 In classical universal definition given by Newton (2013), Force $(F)=$ Mass $(\mathrm{m})$ times acceleration $(F=m a)$.

${ }^{10}$ Force (F) is also inter-exchangeable with term(s) of dialectic anti-contradiction or attraction (as another type of a relation).
} 
with the potential to create the social order and rules for avoiding anomie (i.e., normlessness) in society and social entropy. Thus, even primitive people at a very early stage in the history of social integration created some mutually recognized norms or rules (in their relations) for acceptable or prohibited forms of behavior. These social rules created a common integrated primitive order based on certain common principles, even long before a political organization or a state were created. The primitive common set of norms in order of the pre-state society emerged mainly to reduce damages or price of the social conflicts and contradictions. Therefore, we may conclude that even at the dawn of civilization, people realized the importance of organized binding norms and the necessity of supreme authority (of supra-organizational type) to be established to ensure and guaranty that the binding character of these rules or primitive norms would be respected. The Relationistic methodology could at this point interpret the primitive order and norm-creation as a product of a bandage force (not only contradictions) related to development of common organization and understanding of mutual benefits from the binding order and social institutions. However, that cooperative force appears not to be sufficient per se for the genesis of a state, as the supreme authoritative institution-organization with order-defending organizational capacity and efficiency. Relationism thus comes to the conclusion that along with collective cooperative interaction, the main prerequisite for state-creation was the competitive conflicting interaction that ultimately created institutionalized monopoly of physical force. This new organizational monopoly, as supreme public authority was in fact concentrated in the hands of a few (or sometimes even a one person), officially (legally) empowered to rule at a given (defined) territory over inhabitants controlled as their subjects (i.e., under jurisdiction of a state).

While the primitive (mutually accepted and commonly recognized) rules had emerged as socially necessary tools to create an efficient organized order (as a more preferable or profitable than absence of any organization), the state law nowadays (as a set of binding rules and orders) is essentially based on individual will and is disguised as state's rules of institution that serves as a tool for controlling and governing obedient people (defined as subjects of state). Nevertheless, in the process of transition from the primitive society (with tribal or similar leadership) to the new state order, at some social stage apparently the legal consciousness of the people had been developed, in order to accept the state's justification(s) for the existence of new sovereign authority as legitimate form of subordination or submission. This process of transition (to institutionalized supreme authority) includes variables related to the previous competition for power, but also establishment of common moral knowledge and mutually recognized idea for justified power (re)distribution that finally produced idealistic sense of legitimization (justification) of absolute supreme dominance. Thus, Relationism could define the genesis of a state through the existence of two poles of intensive interaction or a force sufficient enough to produce an official status of sovereignty acceptable for people, subject of that (state) power. One pole in that interaction is the potential (or pole/element) of the organized supreme power, and the other is a pole of the submissive subjects of that dominance; their obedient status were defined by state's rules. The Law of a state defines the obedient state's subjects as people under jurisdiction of that state that have certain public obligations (such as taking orders and respect of laws), and such duties interconnect powerless people with officials (people with status or title) in possession of power. At this point, we should conclude that the law of a state could not emerge before the creation of the official title, i.e., titulus. Therefore, a state could not emerge before the basic element of titulus, i.e., the motivation for such legal creation was apparently the inheritance of titulus as a legal element that served for transfer of official power (right, etc.) to the heirs. 
Unlike the pre-state norms of primitive organized groups (that were created only to avoid spending additional energy on conflicts or dispute-resolutions), the new form of public law of state-organization issued by a state's organization or empowered official dictates to subjects (officials and ordinary people) norms and legally binding sanctioned rules. Thus, from the view of our relationist methodology, the newly created state law, in the moment of its emergence, introduces certain elements of legitimacy that could be defined as a two-way process between two poles of power with an apparently different character in state's status. This new idea of sovereign power and titulus goes "hand with hand" with the idea of legitimacy, where people perceive certain legally-based expectations from the rulers in order to become obedient. That, mutuality and to some extent, sense of imperfect reciprocity of obligatory relation creates a sort of legal consciousness related to rights of people (not just ruler's), as the cultural and political condition for the birth of a state. Therefore, the legal consciousness and legitimacy as a process of relational bandage (into an entity) defines the state as a political organization, where people constantly struggle to improve its status, as well as the justice in the system. In contrary, if the people are unsatisfied, unsuccessful or unhappy in such system, they usually try to escape or join another state system or territory without jurisdiction or political organization.

At this point, it is of utmost importance to point to social recognition of the rules as a law (more or less) generally accepted by the members of the community as binding norms, standards, principles and orders of some authority. After the completion of the state creation process, these rules and norms are again a subject of social and state recognition, as a part of the political process. Thus, in our relationist view, the state's law is a political category, i.e., law is politics and part of the political system. Recognition of the rules in our relationistic approach is merely an extent of the famous doctrine of rules of recognition formulated by Hart (1961) related to the secondary rules (as procedures for creating primary norms, as material law). In our concept, even at the earliest stage of the development of civilization, customary rules had to be mutually socially accepted and thus recognized, and that process later created generally accepted logical legal principles and to some extent more universal logical standards (norm-principles of generally accepted character, such as jus cogens norms). After the genesis of the state, some pre-state customary rules and principles continued to shape the legal understanding of justice and ethics, so to limit arbitrary behavior of everyone and everybody. In that sense basic and developed (moral/legal) principles became a ground for the new concept of legitimacy related to the status of decision-makers (or kings and autocrats) and their expected duties. Main reason for the genesis of the state we found in the need to create the rule(s) that provide the transfer of leader's title (titulus) to the family members as heirs, so that privileged title relating to possession of power (as property) could be subject of inheritance. In primitive society, each common social norm that was created for mutual purposes had to be more or less generally recognized and with some necessary justification as sort of primitive legitimacy that provided social value (for rules/norms) by acceptance (of others, not just single creator). Traditional authority in pre-state society also relied on legitimacy of the accepted decision-maker as authority with the capacity to create rules and take decisions. In such context, as we can derive our conclusion, each norm was initially created by a relation or social interaction(s) that were commonly accepted and sanctioned. The relationist nature of norms was present in the state-organization in form of legitimacy relating to legally based expectations from the rulers (guarantors of norms). Basic relation that creates the state law is the recognition of social-political rules or rules of the state, i.e., sanctioned political principles and norms/rules as governing binding (systemic) elements protected by the supreme organizations (state), where that recognition assumes certain legitimacy and sort of a given consent by subjects (of system or subjects of law or legal-political order). 
Recognition of rules as law is an interactive two-way process between assumed obedient (submissive) subjects and ruling individual(s) or group(s) in possession of state political power who constitute the political elite. Political elite governs and controls the society and its elements in an organized systemic way. It should be noticed that even in the extreme cases when there is a full autocracy as a form of the political system enshrined in the state, law protected by the formal government still has the relational nature (by itself), because rules as given or taken orders always systemically connect the center of the power (i.e., pole of rulers) and the pole of the absence of that potential, i.e., submitted powerless subjects, who on their side must honor the autocratic decisions and orders (as a second interacting pole in that [political] interaction).

From sociological angle, a state as a public and formal political institution, defined essentially by its political system, is only a final product of the process of competition and struggle among individuals and groups for power, and as such that systemic creation represents ultimate monopoly of physical force and dominance in that competitive struggle-process. Competition as relationistic interaction (category of force) at some stage yielded in supreme and independent decision making capacity as formal authority (provided by self-recognized institutions) for creating of law(s) and enforcing them. These processes of legislation and enforcement always depend on the type of political system, as special relationistic integrated order inherently and inseparably built-in the state, as its irreducible essence. Political system is defined by distribution of force and decision-making power within the system, where the character and intensity of force, encompassing institutions and set of rights (as a form of power) determines all relevant elements of a state as bipolar (or multipolar) system of institutionalized force. Therefore, the force is the essence of a state. From a legal point of view, it should also be concluded that such a supreme institutionalized power legally defines the category of sovereignty as a right to sovereignty. This term, besides the supreme domestic authority, legally presupposes subject (of relations) fully independent from any external authority or foreign decision-makers and actors (states or organizations). Indeed, sovereignty (independence of external authority) must be always legally preserved because, together with international (legal) personality, it is an inherently constitutive element of the statehood. Thus, the state is a sovereign international person (subject of law and actor of international relations) and in the same time sovereign domestic authority that exists as an institution formalizing existence of the two interacting opposing poles. In modern international law a state is an entity characterized with: (1) sovereign power; (2) territory; and (3) population of that entity. In our opinion, this set of conditions for qualifying entity as a state should be extended by one more important feature that is indispensably built-in modern statehood: that is the international juridical personality (as capacity to contract, be represented, etc.). Juridical personality as political-legal element historically (in some components) emerged even in the ancient time when diplomatic envoys started to be treated as immune and privileged representatives of states (i.e., kings) and particularly from the moment in history when states begun to contract with each other. If the juridical personality is the essence of a modern state (built-in statehood), we may also conclude that the emergence of the domestic juridical personality indicates general legal nature of the state or statehood. In essence, the state's juridical nature is remarkably similar to the fiction of social contract concept exploited by the Theory of Natural Law for centuries (see liberal political philosophy). In our view, the mentioned dimension of juridical personality (where a state is obliged to their subjects of law, too) revives the old liberal concept of unwritten virtual treaty as a basis for the state creation. States as (international and internal) subjects or persons to significant extent resembles modern international organizations that are indeed products-creations of the intergovernmental treaties (i.e., treaties among their constituent elements—states as contractors). Furthermore, in order to obtain 
full statehood, states needed (and modern state still needs) to obtain a diplomatic (political) recognition, and such processes formally involved legal acts of recognition and bilateral exchange of notes or an agreement. Taking that in consideration, at this point, we can draw a logical conclusion that state creation is in fact dependent on external factors and ultimately based on a recognition agreement of external type, proving its international capacities, thus contributing to the domestic legitimacy.

Domestically, modern states acting as legal persons vis a vis their citizens behave almost as they were bound by a formal treaty or a contract between the state authority and its subjects. This aspect of responsibility that originates from the idea of legitimate power of state and legitimacy (of the government) emerged in the ancient times and later gradually developed, particularly from liberal philosophers and human rights theoretician. Essence of the relation between the governing privileged center (political elite, as a pole) on one side and obedient people (as subjects and other interactive pole) on the other side is recognition of the legitimacy of power and norms, an idea of acceptance that was born along with the existence of actual physical monopoly of force (as an interaction between opposing poles). Thus, the essence of our approach is the new definition of a state as a legal institution-system of political legitimate force, where the relational methodology explains qualitative creationism (developed from the force) of new emerging political institutions empowered with the decision-making rights and sanctions. At a level of physical-relationist definition of the state, for instance, the state authority force (described as intensity of interaction) could be measured as a physical capacity to make people work and behave according to the will of rulers and according to their decisions in form of the binding law. The law therefore represents, in our definition, a political will of the ruling persons or elite empowered with the monopoly of physical and institutional force. The phenomenon of legitimacy on the other side, particularly in modern times, limits the freedom of ruling will and thus intensity of state's force, especially the arbitrary use of force and institutions. The rise of the constitutionalism implemented the idea of legitimacy and formally restricted government, almost as the rulers were under contract, so that the freedom of behavior of rulers and the use of their physical force were subject to regulation and certain level of control by the people, who became subjects of rights (paralleled with obligations) vis a vis state or government. Thus, any constitutional state can be defined as de facto contractual product, where the state contract (that connects government and people) is actually enshrined in the constitution as a sort of generally accepted agreement for conditions of governance.

From the relationistic point of view, even from the first stage of state genesis, in order to minimize social conflicts and avoid the struggle for power, the state invented convenient (form of) legitimacy ${ }^{11}$ for kings that justified their different protected, immune and privileged status (formal position) and titulus as a ruler's prerogative. The idea of convenient legitimacy suitable for a given society was created in same time with the state (as a sort of public justification of status, title and ultimate power). Different justifications were usually based on a myth, religion, traditional or charismatic authority and certain laws created predominantly for preservation of the titulus that could be inherited, by family members (heirs). The royal title, for example, besides military rank, was generally associated with a set of benefits including elite's awards, wealth, fortune, prestige (glory), etc. However, in our systemic concept, legitimacy represents a two-way interacting relational process that functionally eradicates possible state of social anomie (Durkheim, 1982) and political system

\footnotetext{
${ }^{11}$ In relationism, legitimacy is a two-way political process where interactively rulers constantly need to deserve an acceptance of people for their governance, where given consent resembles social contract with virtual legal dimensions described by Natural Law theorists (Locke, 1689). See more about types of legitimacy by Weber (1965).
} 
instability, thus providing conditions for development of elements of force and other interactive features, such as respect for rulers (governance based not only on fear) and even loyalty of people vis a vis rulers and their decisions. In our relationist concept, in order to keep the system working or remaining stable, the basic function of legitimization is providing (and ensuring) existence of political force at the lower/lowest level of invested social and material energy. For existence of a state, a lower social cost for functioning an integrated social system is needed, then in the primitive society that was burdened with constant struggle and constant conflicts.

In comparison to Marxist (Leninist) approach where accumulated contradictions only at some level-stage create a state (Lenin, 1917), our relationistic methodology explains the genesis of the state in much broader and more developed framework. In our theoretical approach, the opposing interactions represent only one type of interaction involved in the definition of state. Basically, all types of interactions can be interpreted as unified social force generally directed to provide a movement of (partially integrated) society, anti-anomie and creative development of social system(s) towards a stronger integration and prosperity. The social interactive poles of different potentials create tension or dynamic charge in the systemic processes of (re)distribution of energy or power. That dynamic charge represents a force encompassing integrated social energy (as a capacity to survive and do more work and production) that includes the needs for integrated organizational efficacy. The interaction of poles, as we may conclude hereby, is endlessly changing in intensity and directed (vectored) towards creation of higher level(s) of organizational efficiency in normative and institutional creational political processes.

Comparing our political concept to the famous theory of goods-exchange and auction formulated by John Rawls (1971), the differences are self-evident. According to Rawls, the only thing that a given member of primitive society knows about themselves is that they are in possession of the basic capacities (goods) necessary to fully and willfully participate in an enduring system of mutual cooperation. Rawls developed the idea of "initial situation" in pre-state society that basic goods were objects of mutual exchange, as in market conditions. Rawls's initial goods (values) placed at very first historic auction were material goods, i.e., fortune, freedom, justice, and security or peace. In that list of values, it was not even taken into consideration the possession of the power and force as a good offered for the exchange or auction. Therefore, fair conditions for initial auction truly never existed. Apparently, social or political power was always the most desirable good.

If we compare our dialectic interpretation of genesis of the state to the theory of state as a protective "association" formulated by Nozick (1974), differences are again self-evident. In essence, we disagree with the Nozick's assumption of state as a private protective institution or a form of association based on the private insurance concept. According to Nozick, such private association existed prior to the state and positive public law as security organizations. These insurance associations were based on a "price” for individual safety. In our concept, it seems that the only "price" that people have to pay for their minimal (acceptable) personal/property safety is not the protection service based on private conditions, but rather the (collective) obedience to the rulers (the power, public in nature).

As explained earlier, there are also constituent international aspects of statehood relevant for the relationistic philosophy of state. These aspects are related to the independence and the protection of the state from external factors, its survival as an entity and especially the recognition of its statehood by other similar foreign entities. Without elements that define the state in relation to external factors, especially the quality of independence and politically recognized sovereignty by other states, it is not at all possible to formulate the process of the state genesis. The state can only come into existence after ending the domestic processes related 
to competition among groups, first for monopolistic power and then for extended domestic sovereignty in international arena.

Moreover, within the relationist approach, the (now structured) element (a state) of the system is regarded as a system on its own, in which the (internal) relations play also a decisive role in its dynamics and define its own systemic variables. The totality of the relations among the elements of international system constitutes the international system of relations. In modern times it is a political system of international relations. On an international arena, the modern relational products that emerged, besides states were international inter-governmental, specialized, regional and universal international organizations, all based on treaties between their member-states. In comparison to the fiction of a social contract enshrined in the Natural Law Theory, i.e., the non-formal social or state treaty creating obligations and rights, the international treaties formally created specialized or universal international organizations, as a new form of international subjects with their constitutional order enshrined in those treaties. These international treaties as legal documents are in format of state-constitution(s) establishing in a single act an administrative and even territorial jurisdiction of the organization. These treaty-constitutions implicitly or explicitly provide for the juridical personality of the organization as a subject of law with all important elements of personality (e.g., capacity to contract, operate with its own property, institute legal proceedings, and possess immunities and privileges of organization itself and their staff, own jurisdiction, and so on). ${ }^{12}$

Thus, in relationism, international organizations based on intergovernmental treaties, represent a new relational formal and institutional product (of relations), as a natural consequence of aspirations for higher level of organized force and systemic needs for power development at international scale. Therefore, relationism at the level of international political system is manifested as a creationism that is motivated by eradication of international anomie and instability (or anarchy), as a functional condition for global development, prospect and further power-centralization at new levels.

\section{Impact of Relationism in the Area of Natural Philosophy and Physics (or Materialism)}

In an attempt to understand the implications of the methodology of relationism, as a general methodology, we shall first try to formulate the origin of the most basic category or phenomena (i.e., the Force) in physics and then apply the definition in our general approach. The main pillars of physics, as a basic science of the natural material world, are formulated in the three famous laws of motion by Newton (2013) that describe and explain the movement and interactive influence among material objects. These pillars or physical laws interpret inertia in the First law, the relation between mass and acceleration in the Second law, and the action-reaction relation in the Third law. Indeed, they describe the relationship between a body and the forces acting upon it, and its motion in response to those forces. While the first law defines the (absence of) Force (F) qualitatively, the second law offers a quantitative measure of the force, and the third asserts that a single isolated force does not exist.

From the angle of General philosophy (Ontology), if the Force is the basic category, then the most fundamental question would be the origin of the force in the universe. This basic question, as we can derive from our previous conclusions, is equivalent to the question of the origin of interaction(s), since every basic interaction (always defined by non-zero intensity) actually represents a force. As we explained in previous

\footnotetext{
${ }^{12}$ See Convention on the Privileges and Immunities of the United Nations (1946), particularly Art. I.
} 
discussion above, there is a logical equivalence between the fundamental relation and the basic interaction of any kind at level of irreducible minimum system $\{\mathrm{E}, \mathrm{N}\}$ or as we can call it a quantum system (i.e., irreducible physical property system). Thus, the fundamental question of the origin of force can be answered by mapping it into previously answered relationist paradox related to origin of everything that exists $\{\mathrm{E}\}$. As we may conclude from the previous discussion about the origin of Everything $\{\mathrm{E}\}$, the question of the existence of force is identical in nature with the mentioned fundamental question of origin $\{\mathrm{E}\}$ and elementaristic paradox, therefore the answer to the second question related to physical force is also identical to the answer (already) given for the origin of Everything. That answer is basically in irreducibility of most fundamental relation, i.e., the natural force is the relationistic irreducible category with inseparable poles. The dilemma in the first paradox of $\{E\}$ was solved by the irreducibility of basic relation linking opposite poles $\{\mathrm{E}\}$ and $\{\mathrm{N}\}$ that are inseparable and impossible to exist out of a system (relation). Within the relationist approach presented in this study, the paradox of existence of the element (related to the process of infinite division of elements) has a resolution or end: The process of infinite division reaches its end at the level of fundamental relation, when the pole of zero quantity and quality cannot be further divided. The non-zero quantity pole (the element E) acquires its existence only in the systemic relation with the zero-quantity pole (the absence of the element). Thus, the ontological question "how come that Everything $(E)$ exists" was resolved when Everything is in a systemic relation with the Nothingness $(N) .{ }^{13}$ Same conclusion can be derived for the existence of Force as an interaction (for philosophical question "how come that Force exists"), since basic interaction appears to be of relationistic nature where pole described as $\{\mathrm{N}\}$ is not self-sufficient, and with different potential than the other pole $\{\mathrm{E}\}$. Therefore, the above formulated question of the origin of Force (F) is reduced to absurd, in an identical way as in the case on non-self-sufficient $\{\mathrm{E}\}$ or $\{\mathrm{N}\}$. Force $(\mathrm{F})$ at some level riches quantum, as the minimum amount of physical property, that cannot be further reduced, and interaction here is logically equivalent to relation where nothingness $\{\mathrm{N}\}$ is not self-sufficient.

In physics, as in logic both mentioned poles $\{\mathrm{E}\}$ and $\{\mathrm{N}\}$ are merely interactive poles since they have different or opposing potentials. Therefore, they apparently represent an interaction. Interactions are always characterized with their intensity. Namely, irreducible basic relation (with poles $\{E\}$ and $\{N\}$ ), in our view, represents the basic physical interaction or a Force $(F)$, which by the systemic logic $\{E\}<->\{N\}$ is irreducible and indestructible. Thus, physical force, as the basic relation, is infinitely ever-existing category (as fundamental quantum), so that within relationist ontology, the above formulated question of the existence of force as interaction becomes meaningless, i.e., absurd because a basic interaction is equivalent to basic relation. The difference of potentials of both poles interactively creates charge equal to $p_{1}-p_{2}$ (where $p$-potential of the pole) or symbolically $\Delta p$ (i.e., change of potential). This $\Delta p$ in time ( $\Delta t)$ is the essence of any force in the nature.

Let us apply now our relationistic approach in physics. The typical easiest example is the Electromotive force (EMF or shortly E). In physics, this (electrical) force is defined as a deference of the poles possessing different potential and creating a charge (between those uneven potentials). ${ }^{14}$ So, generally in physics, it appears that whenever exists a deference of the uneven poles that thus create charge, the charge causes movement or change (dynamics). Thus, the paradox noticed by philosophers from ancient time to present (i.e., reason for universal movement) can be resolved generally in Marxist dialectical terms as a consequence of the

\footnotetext{
13 Thus, within a relationist ontology the above formulated most fundamental question becomes meaningless, i.e., it is reduced to absurd. We argue here that the same applies to the question of the origin of natural force (F), with same logical explanation.

${ }^{14}$ A Voltage difference or charge with capacity to produce a work or material change.
} 
dialectical contradiction. But apparently, a more accurate definition of the origin of movement would be the existence of an inherent force as an universal and most fundamental dynamic category (that encompass both contradictions and non-contradictions), where the reason for change or movement of any kind is enshrined in the category itself. Furthermore, in the definition given by Newton, the change of velocity ( $v$ ) (defined as $\Delta v$ ) is possible only if object is subjected to the influence of some external force (F), and therefore change of velocity in time (or acceleration) is proportional to the intensity of force that influenced movement of that object (assuming that the mass $\mathrm{m}$ is constant). This force (F) actually represents a change of the mechanical momentum, with the same type of equation $\Delta p(p=m v)$, so that we may interpret it as differential of mechanical potentials (acting as poles), i.e., $F=\Delta p /(\Delta t)=m a$. In relationism, due to the constant dialectic tendency to changes in the nature of $\{\mathrm{E}\}$, charge variations of both mutually dependent poles will occur and will generate further dynamics in $\{\mathrm{E}\}$. In natural world (explained by physics), a cause of the potential-variations and changes in $\{E\}$ could be attributed to $\{N\}$, due anti-symmetry $\{N\} \not \equiv\{N\}$ ) in a way that $\{\mathrm{N}\}$ may not always be an absolute zero-value, but rather $\{\mathrm{N}\} \rightarrow 0$. Therefore, there is a constant change of intensity between interacting poles due to the variations in poles' potentials. It should be noted that in the Newton's Second law of movement the basic equation $F=m a$, replaced with the definition using a change in mechanical momentum $p_{1}-p_{2}\left(p_{i}=m v\right)$, or shortly $\Delta p$, with our interpretation as externally induced differences between poles with potentials, is equivalent to mentioned EMF definition. The Newton's definition of external force (as momentum differentiation) is, in fact, equivalent to the uneven internal differentiation of the poles (in a sense that each momentum could be understood as object with different mechanical potential). Therefore, the Newton's external force is simply defined as proportional (impact) to acceleration (change of speed) of material object, were mass $(\mathrm{m})$ of that object is inversely proportional category (defined as measurement of inertia against acceleration). The apparent mathematical equivalence of that equation (in form $\Delta p$ ) with the equation related to potential differentiation of internal interactive poles $\{E\}<->\{N\}$, once again points to the general conclusion that force is a dynamical category that inherently encompass dynamical change or acceleration in itself.

What could be a possible contribution of our relationistic approach for physics is that not only the physical energy (E) is indestructible category (taking into consideration mass-energy equivalence ${ }^{15}$ ), but also the force possesses the same feature of indestructible and inherent nature.

A difference of our relational method from classical methodology, is that it has a potential of transcending the materialistic substance interpretation (of everything), thus expanding logic beyond the traditional chains of materialism. Namely, the relationism does not need to define the nature of basic poles (the pole of everything $\{\mathrm{E}\}$ ), since our presented logic only determines the fundamental relation, but not its substance. ${ }^{16}$ What

\footnotetext{
15 Anything having energy (E) exhibits a corresponding mass (m) given by its energy (E) divided by the speed of light squared, or $E=m c^{2}$. See Einstein (1905).

16 There is no need to presume that basic substance is (exclusively) materialistic one. From metaphysical point of view, it can be observed that basic relation $(\{\mathrm{E}\} *\{\mathrm{~N}\})$ may be described as the open-system basic entity under operator (were * — symbolizing operator or relation $(<->)$ between poles), so that such entity may again be subjected to same operator (* with the pole $\mathrm{N})$ in the logical form of $(\{E\} *\{N\}) *\{N\}$, without causing logical inconsistency e.g., $((\{E\} *\{N\}) *\{N\}) *\{N\}$, and so on... to infinity. So, the basic system $(\{\mathrm{E}\} *\{\mathrm{~N}\})$ thus may evolve and create new structures added to pole $\{\mathrm{E}\}$ with limitless dimensions, although from the point of physics that may not be physically possible (because that creationism would probably have some final end). Furthermore, it should be observed that if we replace pole $\{E\}$ with informational sub-element $(1)$ and pole $\{N\}$ with the informational sub-element (0), basic system becomes $(\{1\},\{0\})$ or informational irreducible sub-bit of $(1,0)$, suggesting new possibilities of research on whether our knowing universe is in fact basically some kind of informational ("computational”) one, bringing discussion of the substance of universe again under considerations.
} 
perhaps could be a further philosophical contribution for physical explanation of constantly expanding natural fields and space (i.e., physical fields after universe creation (in Bing-Bang theory processes)), is our dynamical interpretation of force prone to be self-developed, and thus the suggestion to research in physics to take into consideration the possible creationistic model of the universe.

\section{Conclusion}

In the present article, the goal of our research is to provide an answer to the fundamental ontological question: Why Everything (that) exits? (and not just nothing?). In our analyses, we discovered that this fundamental question was identical to the formal-logic puzzling question related to the solution of the problem of elementaristic paradox. Furthermore, our new methodological concept (or philosophy) of relationism solves the question of elementaristic paradox and gives an answer to the basic ontological question of existence (of everything). In our study of logical operations, we concluded that Everything that exits (E) and Nothingness (N) represent logically irreducible (systemic) relation and that (E) and (N) are inseparable and in contradiction to each other. These basic elements are mutually connected as an interaction, forming a system of interacting poles where Nothingness $(\mathrm{N})$ may not be possible without the other pole (E). The most essential characteristic of this system is the intrinsic inter-connection of $\mathrm{E}$ and $\mathrm{N}$ without which neither of them can exist, nor the system they form could exist. This intrinsic inter-connection of $\mathrm{E}$ and $\mathrm{N}$ in the system constitutes a relation between $\mathrm{E}$ and $\mathrm{N}$ that makes the system possible, and thus reduces the basic ontological question of philosophy (Why Everything [that] exits?) to absurd. The basic system $\{E, N\}$ or entity ( $\{E\},\{N\})$ resolves the mentioned elementaristic paradox, and in same time solves the basic ontological question. In this article, we also explained that the basic system $(\{\mathrm{E}\},\{\mathrm{N}\})$ as a fundamental interaction, can evolve due to intrinsic contradictions manifested as a force (a category related to the measurement of intensity of interaction caused by differences of the poles $\{\mathrm{E}\}$ and $\{\mathrm{N}\}$ in their potentials).

A general conclusion derived from this study is that the force from the basic relation $(\{E\},\{N\})$ is the most fundamental category that causes (any) system to move or change, regardless of its nature or substance (i.e., idea or material substance).

Analyzing the mainstream political theories, we have found out that the constant competition and struggle for force among social groups finally resulted in the formal recognized monopoly of force necessary for the genesis of state and its law (sovereign right(s)) in the same historical moment. The genesis of the state includes legitimacy of sovereignty, as a systemic relational product of social interactions. The basic conclusion related to the genesis of the state is that this sovereign institution emerged in history in the moment when the idea of titulus (a title of leader/ruler) subject of inheritance was (publicly) born. For practical operation of that idea, rulers (i.e., first kings, as successor of primitive tribal chiefs/leasers) developed and established legitimacy for justification of their titulus, combined with the appropriate binding rules or public law related to that supreme title. The state could not come into being before the moment when society accepted and recognized the transferable title (for their previously tribal chiefs).

\section{References}

Durkheim, E. (1982). Rules of sociological method (2nd ed.). New York: Free Press.

Einstein, A. (1905). Does the inertia of a body depend upon its energy-content? Retrieved from https://www.fourmilab.ch/etexts/einstein/E_mc2/e_mc2.pdf

Engels, F. (1968). Dialectic of nature. New York: International Publishers. 
Erman, J. (1979). Was Leibniz a relationist? In “Studies of metaphysics”, midwest studies in PH (Vol. IV, p. 277). Minnesota: University of Minnesota Press.

Gilpin, R. (1981). War and change in world politics. Cambridge: Cambridge University Press.

Hart, H. L. (1961). The concept of law. Oxford: Oxford University Press.

Hegel, G. F. W. (1977). Phenomenology of spirit. Oxford: Clarendon Press.

Heidegger, M. (2000). Introduction to metaphysics. New Haven, Connecticut: Yale University Press.

Janev, I. (2013). Relationist approach to international political theory. Международные научныеисследования, (1-2). Retrieved from

https://www.researchgate.net/publication/338824567_Igor_Janev_Relationist_Approach_to_International_Political_Theory_ Mezdunarodnye_naucnye_issledovania_No_1-2

Lenin, V. (1917). The state and revolution. London: Aziloth Books.

Locke, J. (1689). Two treatises of government. London: Awnsham Churchill.

McTaggart, J. (2005). Studies in Hegelian dialectic. Cambridge: Cambridge University Press.

Merton, R. K. (1996). On social structure and science. Chicago: The University of Chicago Press.

Newton, I. (2013). The principia: Mathematical principles of natural philosophy. Cambridge: Trinity College. (originally published 1688)

Nozick, R. (1974). Anarchy, state, and utopia. New York: Basic Book.

Rawls, J. (1971). A theory of justice. Belknap Press.

Ray, C. (2008). Time, space and philosophy. Amsterdam: Elsevier.

Von Bertalanfly, L. (1971). General systems theory. London: Penguin Press.

Waltz, K. N. (1979). Theory of international politics. New York: Random House.

Weber, M. (1965). Politics as a vocation. Philadelphia: Fortress Press. 